\title{
SCIDiC
}

\author{
International Journal of Dentistry and Oral Science (IJDOS) \\ ISSN: 2377-8075
}

\section{Working Length Determination in Mandibular Primary Second Molars - A Retrospective Study}

Research Article

Godlin Jeneta $J^{1}$, Mahesh Ramakrishnan ${ }^{2 *}$

${ }^{1}$ Saveetha Dental College and Hospitals, Saveetha Institute of Medical and Technical Sciences, Saveetha University, Chennai, India.

${ }^{2}$ Professor, Department of Pedodontics, Saveetha Dental College and Hospitals, Saveetha Institute of Medical and Technical Sciences, Saveetha University, Chennai, India.

\section{Abstract}

Working length determination is an important step for a successful root canal therapy in deciduous or permanent teeth. The main objective of this study is to evaluate the association between age, gender, tooth number, number of visits with working length of mandibular second primary molar. This was a retrospective, institutional based study. Sample size was 298. Data about patients below 18 years who underwent root canal treatment in the mandibular second primar molar in a period of june 2019 to march 2020 were collected. Excel tabulation was done and data was transferred to SPSS software. T test and pearson correlation was done to compare the age, gender, tooth number, number of visits with working length. $\mathrm{p}<0.05$ was considered statistically significant. The mean age of males was $5.59 \pm 1.8$ and females was $5.68 \pm 2.2$. The mean working length of males was $12.04 \pm 2.8$ and females was $12.34 \pm 2.8$. There was a statistical significant association found between the number of visits and working length. There was no statistical association found between age and working length, gender and working length, tooth number and working length.

Keywords: Mandibular Primary Second Molar; Radiography; Working Length.

\section{Introduction}

Successful endodontic treatment in a primary teeth plays an important role in preservation of dentition until the completion of physiologic exfoliation [1]. The primary objective of pulpectomy in deciduous teeth is to retain the teeth in a symptom free state and to maintain the arch form [2].

Determination of root canal working length is considered as one of the most important steps in endodontic treatment [3]. Proper detection working length is important prior to pulpectomy in primary teeth. Working length should be measured from the coronal pont to the site where the root canal ends. The working length should be accurate because it influences the success of the root canal treatment directly [4]. Errors in working length determination may cause the instrument to go beyond the apical foramen causing extravasation of irrigating solutions and restorative materials leading to postoperative pain. In primary tooth, the instrumentation beyond the apex may damage the permanent tooth germ [5].

There are various methods for determining the working length of primary teeth such as tactile sensation method, conventional radiography, radio visiography and the electronic apex locator method [6]. Radiography is the most common techniques followed and widely use for determining the working length [7]. Conventional radiography has been generally used to determine the working length. There are some disadvantages in this method such as superposition of anatomical structures, image distortion and processing time [8]. In radiovisiography method, a sensor is used instead of film which reduces the processing time,has less radiation exposure and allows image editing making it easy to examine the details [9]. The apex locators were developed to determine working length without radiation exposure and has been used for over 40 years [10]. There are various generations of apex locators. Apex locators are gaining popularity nowadays and has been used in permanent teeth in recent years to estimate the working length of the root canal and increase the precision rate of endodontic treatment [11]. Apex locators apart from reducing the unneces-

*Corresponding Author:
Mahesh Ramakrishnan,

Professor, Department of Pedodontics, Saveetha Dental College, Saveetha Institute of Medical and Technical Sciences, Saveetha University, 162, PH Road, Chennai 600077, Tamil Nadu, India.

Tel: 9840322728

E-mail: mahesh@saveetha.com

Received: September 05, 2019

Accepted: September 29, 2019

Published: September 302019

Citation: Godlin Jeneta J, Mahesh Ramakrishnan. Working Length Determination in Mandibular Primary Second Molars - A Retrospective Study. Int J Dentistry Oral Sci. 2019;S7:02:003:10-14. doi: http://dx.doi.org/10.19070/2377-8075-SI02-07003

Copyright: Mahesh Ramakrishnan 2019. This is an open-access article distributed under the terms of the Creative Commons Attribution License, which permits unrestricted use, distribution and reproduction in any medium, provided the original author and source are credited. 
sary exposure to radiation has been shown to reduce clinical time. Due to these, its use in primary teeth is recommended [12].

Our department is passionate about child care, we have published numerous high quality articles in this domain over the past 3 years [13-31]. With this inspiration we planned to pursue research on the working length determination in mandibular primary second molars.

The objective of this study is to determine the working length of the mandibular primary second molars and associate it with age, gender and tooth number.

\section{Materials and Methods}

The study was in a University setting. Study includes patients who underwent crown lengthening in the anterior region (aesthetic zone). Sample size is 243 . The study was a retrospective unicentric observational study. Ethical approval from university ethics committee. Data was collected from DIAS where the dental and medical history of the patients were recorded. The data tabulation done in excel sheet and transferred to SPSS for data analysis. Chisquare test was done.

\section{Study Design}

This was a retrospective study conducted in a private dental institution. The patient case records were reviewed for the necessary information by a trained examiner. The advantage of conducting the study in an institutional set up provides easy access to patient records. Among patients who have visited the dental clinic of the institution, the information of 243 teeth was reviewed. A age range of under 18 was selected for the study. The institutional ethical committee provided approval for the study (SDC/ SIHEC/2020/DIASDATA/0619-0320).

\section{Inclusion criteria}

1. Patients who had undergone pulpectomy in mandibular primary second molars

2. Patients from below 18 years of age

\section{Exclusion criteria}

1. Incomplete patient data

2. Duplicate patient data

3. Pulpectomy in other primary teeth other than mandibular primary second molars.

\section{Sampling}

A total of 243 tooth sites of patients who underwent pulp therapy were reviewed for the tooth number, age, working length and gender. Convenient sampling method was used to select the patients for the study. The data obtained from the case records were cross verified with photographs.

\section{Data collection}

All the data after thorough checking for duplicates, incomplete entries and cross verification with photographs were entered in
Microsoft excel spread sheet in order to organise the data. The variables obtained from the data included age, gender, arch, and reason for crown lengthening. Here the age, gender, tooth number are the independent variables and, working length is the dependent variable.

\section{Statistics}

The statistical analysis of the obtained data was performed by the SPSS software version 23.0. The data from the excel spreadsheet was transferred to SPSS software for analysis. Chi square tests were employed in order to find the association between different variables. The $\mathrm{p}$ value less than $5 \%$ was considered statistically significant. The final results are presented in the form of graphs for further interpretation and discussion.

\section{Results and Discussion}

One of the most important steps for successful pulp therapy is to determine the working length accurately. Working length determination plays an important role to avoid possible damage to the underlying permanent teeth bud, periradicular tissue injury or infection due to over instrumentation [32]. There are not much studies on the working length of primary mandibular second molars.

A total of 243 mandibular second primary molars were included in this study. All these are root canal treated teeth. The mean age of the boys and girls were $5.59 \pm 1.8$ and $5.68 \pm 2.2$ respectively. The mean working length of boys and girls were $12.04 \pm 2.8$ and $12.34 \pm 2.8$ respectively. A study by Koruyucu stated that the working length of primary teeth present in the lower jaw is 12.73 $\pm 1.76[7]$.

The distribution of age and the working length were studied in that individuals below 5 years had $16.46 \%$ of teeth with working length less than 10 and $37.45 \%$ of teeth with working length between 11 to 20 . Individuals of age group 5 to 10 had $12.35 \%$ of teeth with working length less than $10,32.10 \%$ of teeth with working length between 11 to 20 and $0.41 \%$ of teeth above 21 . Individuals of age group above 11 had $0.41 \%$ of teeth with working length less than $10,0.82 \%$ of teeth with working length between 11 to 20. There was no statistically significant association found $(p=0.471)$. However, working length of 11 to 20 was more prevalent below 5 years. (Figure 1)

The distribution of tooth number and the working length were studied in that the mandibular left second primary molar had $16.05 \%$ of teeth with working length below $10,32.92 \%$ of teeth with working length between 11 and $20,0.41 \%$ of teeth with working length above 21 . Mandibular right second primary molar had $13.17 \%$ of teeth with working length below 10 and $37.45 \%$ of teeth with working length between 11 and 20. There was no statistically significant association found $(p=0.307)$. However, working length of 11 to 20 was more prevalent in 85 . (Figure 2)

The distribution of gender and the working length were studied in that males had $17.28 \%$ of teeth with working length below 10 and $39.51 \%$ of teeth with working length between 11 and 20 . Females had $11.93 \%$ of teeth with working length below $10,30.86 \%$ of teeth with working length between 11 and $20,0.41 \%$ of teeth with working length above 21 . There was no statistically signifi- 
Figure 1. Depicts the association between the age and the working length. $\mathrm{X}$ axis represents the age and $\mathrm{Y}$ axis represents the total number pulpectomy done in mandibular second molars. From the present graph it can be inferred that the association between the variables is statistically not significant ( $p$ value $=0.471 ; p>0.05$ ). However, working length of 11 to 20 was more prevalent below 5 years and between 6 to 10 years.

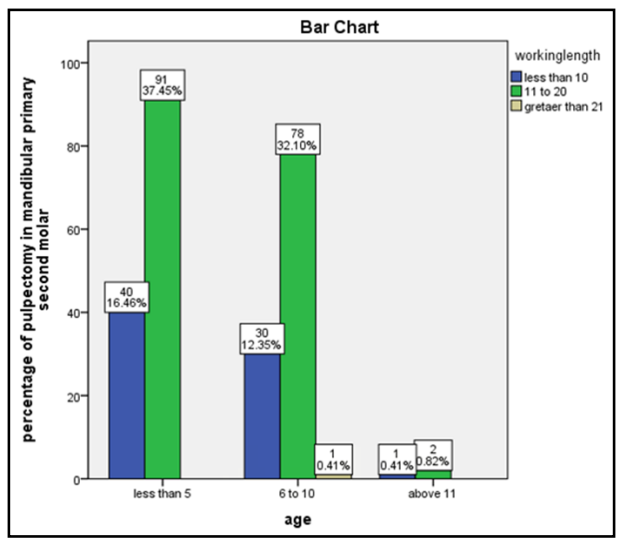

Figure 2. Depicts the association between the tooth number and the working length. $X$ axis represents the tooth number and $\mathrm{Y}$ axis represents the total number pulpectomy done in mandibular second molars. From the present graph it can be inferred that the association between the variables is statistically not significant ( $p$ value $=0.307 ; p>0.05)$. However, working length of 11 to 20 was more prevalent in 85 .

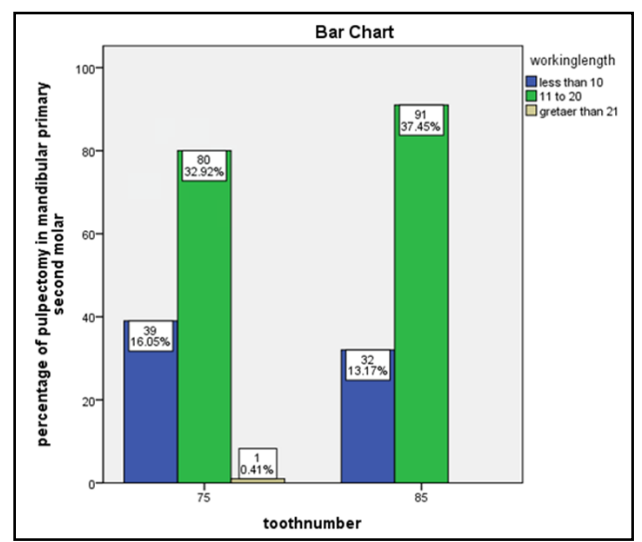

Figure 3. Depicts the association between the gender and the working length. $\mathrm{X}$ axis represents the gender and $\mathrm{Y}$ axis represents the total number pulpectomy done in mandibular second molars. From the present graph it can be inferred that the association between the variables is statistically not significant ( $\mathrm{p}$ value $=0.471 ; \mathrm{p}>0.05$ ). However, working length of 11 to 20 was more prevalent in males.

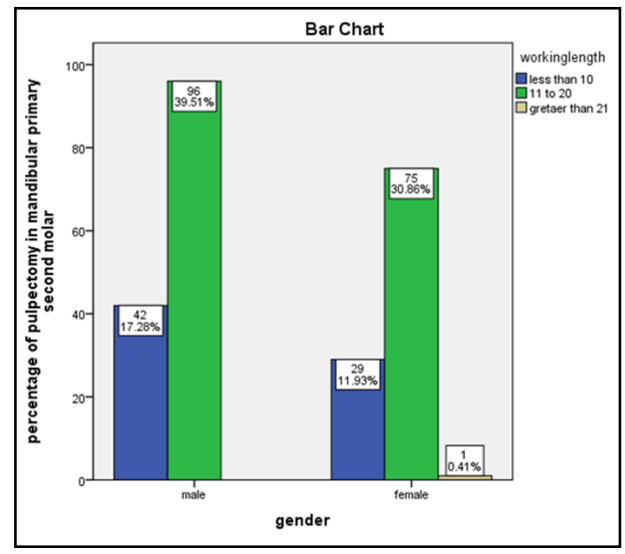

cant association found $(\mathrm{p}=0.471)$. However, working length of 11 to 20 was more prevalent in males. (Figure 3)

The distribution of number of visits and the working length were studied in that single visit had $25.51 \%$ of teeth with working length below 10 and $57.20 \%$ of teeth with working length between 11 and 20. Multi visits had 3.70\% of teeth with working length below $10,13.17 \%$ of teeth with working length between 11 and $20,0.41 \%$ of teeth with working length above 21 . Statisti- cal significance was found between number of visits and working length $(\mathrm{p}=0.048)$. Working length of 11 to 20 was more prevalent in single visits. (Figure 4)

Limitations of this study include small sample size and subjective bias. Future study should be conducted with a wide range of population. 
Figure 4. Depicts the association between the number of visits and the working length. $X$ axis represents the number of visits and $\mathrm{Y}$ axis represents the total number pulpectomy done in mandibular second molars. From the present graph it can be inferred that the association between the variables is statistically significant ( $p$ value $=0.048 ; p<0.05$ ).

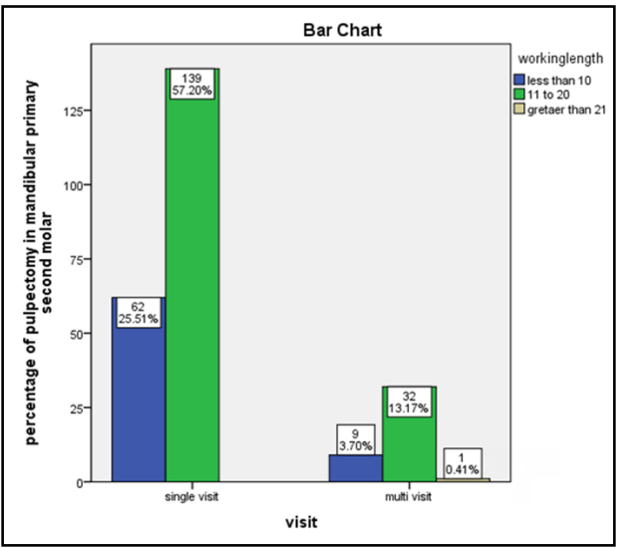

\section{Conclusion}

Within the limitation of the study, we can conclude that there is a significant difference between the number of visits and working length. There was no statistical significance found between age and working length, gender and working length, tooth number and working length. Working length of 11 to 20 was more prevalent than working length less than 10 or above 21 .

\section{References}

[1]. American Academy on Pediatric Dentistry Clinical Affairs Committee-Pulp Therapy subcommittee. American Academy on Pediatric Dentistry Council on Clinical Affairs: Guideline on pulp therapy for primary and young permanent teeth. Pediatr. Dent.. 2009;30(7):170-4.

[2]. Rodd HD, Waterhouse PJ, Fuks AB, Fayle SA, Moffat MA, British Society of Paediatric Dentistry. Pulp therapy for primary molars. Int J Paediatr Dent. 2006 Sep;16Suppl 1:15-23

[3]. Özsezer E, İnan U, Aydın U. In vivo evaluation of ProPex electronic apex locator. J Endod. 2007 Aug 1;33(8):974-7.

[4]. Pereira KF, Silva PG, Vicente FS, Arashiro FN, Coldebella CR, Ramos CA. An in vivo study of working length determination with a new apex locator. Braz Dent J. 2014 Jan-Feb;25(1):17-21.Pubmed PMID: 24789286

[5]. Basso MD, Jeremias F, Cordeiro RC, Santos-Pinto L. Digital radiography for determination of primary tooth length: in vivo and ex vivo studies. ScientificWorldJournal. 2015;2015:939045. doi: 10.1155/2015/939045. Epub 2015 Feb 23.Pubmed PMID: 25802894.

[6]. Wankhade AD, Kumar R, Singh RK, Chandra A. Root canal length determination by different methods in primary teeth: an in vivo study. Pediatr Dent. 2013 Mar-Apr;35(2):E38-42.Pubmed PMID: 23635968.

[7]. Koruyucu M, Bayram M, Kasımoğlu Y, Seymen F. Comparison of root canal length measurement methods in primary teeth. Dentistry 3000. 2018 Jul $13 ; 6(1): 8-16$

[8]. Orosco FA, Bernardineli N, Garcia RB, Bramante CM, Duarte MA, Moraes IG. In vivo accuracy of conventional and digital radiographic methods in confirming root canal working length determination by Root ZX. J Appl Oral Sci. 2012 Sep-Oct;20(5):522-5.Pubmed PMID: 23138737.

[9]. Ellingsen MA, Hollender LG, Harrington GW. Radiovisiography versus conventional radiography for detection of small instruments in endodontic length determination. II. In vivo evaluation. J Endod. 1995 Oct;21(10):51620.Pubmed PMID: 8596074.

[10]. Sunada I. New method for measuring the length of the root canal. J Dent Res. 1962 Mar;41(2):375-87.

[11]. ElAyouti A, Weiger R, Löst C. The ability of root ZX apex locator to reduce the frequency of overestimated radiographic working length. J Endod. 2002 Feb;28(2):116-9.Pubmed PMID: 11833683.

[12]. Oznurhan F, Ünal M, Kapdan A, Ozturk C, Aksoy S. Clinical evaluation of apex locator and radiography in primary teeth. Int. J. Paediatr. Dent. 2015 May;25(3):199-203.

[13]. Ravikumar D, N S, Ramakrishna M, Sharna N, Robindro W. Evaluation of McNamara's analysis in South Indian (Tamil Nadu) children between 8-12 years of age using lateral cephalograms. J Oral BiolCraniofac Res. 2019 Apr-
Jun;9(2):193-197.Pubmed PMID: 31211035

[14]. Ravikumar D, Gurunathan D, Gayathri R, Priya VV, Geetha RV. DNA profiling of Streptococcus mutans in children with and without black tooth stains: A polymerase chain reaction analysis. Dent Res J. 2018 SepOct;15(5):334-339.Pubmed PMID: 30233653.

[15]. Ravikumar D, Jeevanandan G, Subramanian EM. Evaluation of knowledge among general dentists in treatment of traumatic injuries in primary teeth: A cross-sectional questionnaire study. Eur J Dent. 2017 Apr;11(2):232-7.

[16]. Ravindra V, Rekha V, Annamalai S, Sharmin D, Norouzi-Baghkomeh P. A comparative evaluation between dermatoglyphic patterns and different terminal planes in primary dentition. J ClinExp Dent. 2018 Dec 1;10(12):e1149-e1154.Pubmed PMID: 30697372.

[17]. Ravindra V, Rekha CV, Annamalai S, Sharmin DD, Norouzi-Baghkomeh P. A comparative evaluation between cheiloscopic patterns and the permanent molar relationships to predict the future malocclusions. J ClinExp Dent. 2019 Jun 1;11(6):e553-e557.Pubmed PMID: 31346376.

[18]. Govindaraju L, Jeevanandan G, Subramanian EMG. Comparison of quality of obturation and instrumentation time using hand files and two rotary file systems in primary molars: A single-blinded randomized controlled trial. Eur J Dent. 2017 Jul-Sep;11(3):376-379.Pubmed PMID: 28932150.

[19]. Govindaraju L, Jeevanandan G, Subramanian EM. Knowledge and practice of rotary instrumentation in primary teeth among Indian dentists: a questionnaire survey. J Int Oral Health. 2017 Mar 1;9(2):45.

[20]. Nair M, Jeevanandan G, Vignesh R, Subramanian EM. Comparative evaluation of post-operative pain after pulpectomy with k-files, kedo-s files and mtwo files in deciduous molars-a randomized clinical trial BDS. $2018 \mathrm{Oct}$ 24;21(4):411-7.

[21]. Jeevanandan G, Ganesh S. Kedo file system for root canal preparation in primary teeth. Indian J Dent Res. 2019 Jul 1;30(4):622-4.

[22]. Panchal V, Jeevanandan G, Subramanian E. Comparison of instrumentation time and obturation quality between hand K-file, H-files, and rotary Kedo$S$ in root canal treatment of primary teeth: A randomized controlled trial. J Indian SocPedodPrev Dent. 2019 Jan-Mar;37(1):75-79.Pubmed PMID: 30804311.

[23]. Subramanyam D, Gurunathan D, Gaayathri R, Vishnu Priya V. Comparative evaluation of salivary malondialdehyde levels as a marker of lipid peroxidation in early childhood caries. Eur J Dent. 2018 Jan-Mar;12(1):67-70. Pubmed PMID: 29657527.

[24]. Vignesh R, Sharmin D, Rekha CV, Annamalai S, Baghkomeh PN. Management of Complicated Crown-Root Fracture by Extra-Oral Fragment Reattachment and Intentional Reimplantation with 2 Years Review. ContempClin Dent. 2019 Apr-Jun;10(2):397-401.Pubmed PMID: 32308309.

[25]. Ramadurai N, Gurunathan D, Samuel AV, Subramanian E, Rodrigues SJ. Effectiveness of $2 \%$ Articaine as an anesthetic agent in children: randomized controlled trial. Clin Oral Investig. 2019 Sep 1;23(9):3543-50.

[26]. Panchal V, Gurunathan D, Shanmugaavel AK. Smartphone application as an aid in determination of caries risk and prevention: A pilot study. Eur J Dent. 2017 Oct-Dec;11(4):469-474.Pubmed PMID: 29279672.

[27]. Panchal V, Jeevanandan G, Subramanian EMG. Comparison of post-operative pain after root canal instrumentation with hand K-files, $\mathrm{H}$-files and rotary Kedo-S files in primary teeth: a randomised clinical trial. Eur Arch Paediatr Dent. 2019 Oct;20(5):467-472.Pubmed PMID: 30864090.

[28]. Jeevanandan G, Govindaraju L. Clinical comparison of Kedo-S paediatric rotary files vs manual instrumentation for root canal preparation in primary molars: a double blinded randomised clinical trial. Eur Arch Paediatr Dent. 
2018 Aug;19(4):273-278.Pubmed PMID: 30003514.

[29]. Samuel SR, Acharya S, Rao JC. School Interventions-based Prevention of Early-Childhood Caries among 3-5-year-old children from very low socioeconomic status: Two-year randomized trial. J Public Health Dent. 2020 Jan;80(1):51-60.Pubmed PMID: 31710096.

[30]. Ramakrishnan M, Dhanalakshmi R, Subramanian EMG. Survival rate of different fixed posterior space maintainers used in Paediatric Dentistry - A systematic review. Saudi Dent J. 2019 Apr;31(2):165-172.Pubmed PMID: 30983825 .
[31]. Vishnu Prasad S, Kumar M, Ramakrishnan M, Ravikumar D. Report on oral health status and treatment needs of 5-15 years old children with sensory deficits in Chennai, India. Spec Care Dentist. 2018 Jan;38(1):58-59. Pubmed PMID: 29333605.

[32]. Silva EJ, Herrera DR, Souza-Júnior EJ, Rosa TP. Evaluation of the multifrequency electronic apex locator Joypex 5 in primary teeth. Eur Arch Paediatr Dent. 2014 Feb;15(1):51-4.Pubmed PMID: 23881737. 